\title{
Value for Money and Hospital Pharmacists
}

\author{
Neil J MacKinnon
}

${ }^{6} V^{2}$ alue for money" is a phrase uttered seemingly everywhere in health care today. In 2009, the Health Council of Canada released a report on this topic, ${ }^{1}$ and 3 reports on the value for money of physicians, pharmaceuticals, and diagnostics, respectively, will be published this year. If the Council were to produce a report on hospital pharmacists, what would such a report conclude? Have you ever reflected on the value that you bring to your employer and, ultimately, to your patients?

Quantitatively, the recent literature has yielded a wealth of evidence on the value of hospital pharmacists. In a summary of 15 studies that evaluated clinical pharmacy services, the pooled benefit-to-cost ratio was 4.81 to 1 . In other words, reductions in costs or other economic benefits worth US $\$ 4.81$ were achieved for each US\$1 spent on clinical pharmacy services. ${ }^{2}$ In a systematic review of 36 studies, Kaboli and others ${ }^{3}$ identified 5 interventions by clinical pharmacists that improved outcomes for hospital patients. In addition, in an observational study of almost 3 million patients in US hospitals, 7 clinical pharmacy services were associated with reductions in mortality rate. ${ }^{4}$

Qualitatively, there is also much evidence supporting hospital pharmacy practice. In a commentary in the Journal of the American Medical Association (JAMA), Jerry Avorn, ${ }^{5}$ a physician, commented on "the important but often unnoticed role of the hospital pharmacist. Few physicians appreciate the quiet yet vital role played by these unassuming colleagues who make it possible for us to propel potions of powerful chemicals through the veins and into the guts of acutely ill inpatients each day, with (all things considered) remarkably few nasty surprises." He went on to argue that "A surgeon who repairs an aortic aneurysm before it ruptures is rightly seen as a hero who saved the patient's life; rarely is similar glory accorded a pharmacist who stops a dose of oxacillin before it reaches a patient with an anaphylaxis-producing penicillin allergy." While we may not entirely agree with the characterization of our profession as "unassuming", we can certainly attest to Avorn's premise.
Some of you have heard me speak about "the pharmacist narcotic effect". By this I mean that some physicians may be skeptical of the value of pharmacists, but when they finally have the opportunity to work closely with a clinical pharmacist and personally experience the value that this individual brings to

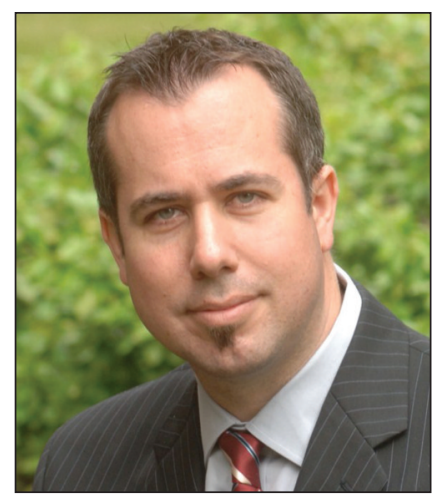
the health care team, they become "addicted" to the role of the pharmacist. Should the pharmacist leave the team, the physician goes into "withdrawal" and asks for a replacement pharmacist. So, go out there and demonstrate your value to your health professional colleagues and to your patients and leave them wanting more.

\section{References}

1. Value for money: making Canadian health care stronger. Toronto (ON): Health Council of Canada; 2009. Available from: www.healthcouncilcanada.ca/ docs/rpts/2009/HCC_VFMReport_WEB.pdf

2. Perez A, Doloresco F, Hoffman JM, Meek PD, Touchette DR, Vermeulen LC, et al. Economic evaluations of clinical pharmacy services: 2001-2005. Pharmacotherapy 2008;28(11):285e-323e.

3. Kaboli PJ, Hoth AB, McClimon BJ, Schnipper JL. Clinical pharmacists and inpatient medical care: a systematic review. Arch Intern Med 2006; 166(9):955-964.

4. Bond CA, Raehl CL. Clinical pharmacy services, pharmacy staffing, and hospital mortality rates. Pharmacotherapy 2007;27(4):481-493.

5. Avorn J. Putting adverse drug events into perspective. JAMA 1997; 277(4):341-342.

Neil J MacKinnon, BSc(Pharm), MSc(Pharm), PhD, FCSHP, is President Elect and Vision Liaison of CSHP. 